\title{
Sustainable architecture: trends in higher professional architectures' education
}

\author{
Svetlana Kuzmina*1, Natalia Morozova ${ }^{2}$, Anna Pimenova $^{3}$, Alena Agafonova ${ }^{4}$ \\ ${ }^{1}$ Peter the Great Saint-Petersburg Polytechnic University, St. Petersburg, Russia \\ ${ }^{2}$ Saint-Petersburg State Forest Technical University, 5, Institutskiy per., Saint-Petersburg, Russia \\ ${ }^{3}$ Saint-Petersburg State University of Economics, 21, Sadovaya st., Saint-Petersburg, Russia \\ ${ }^{4}$ Saint-Petersburg State University, 7-9, Universitetskaya Emb., Saint-Petersburg, Russia
}

\begin{abstract}
In the article we tried to investigate theoretical ideas concerning actual students' reasons for education in the field of architecture in frame of the second level of higher professional education system. We present the results of survey that we conducted last year. We collected data about students' reasons to enrol for architectures' and others master programmes and their expectations of programmes' content, programmes' volume, curriculum structure, placement periods. We analysed the teaching methods, structure and trends in architecture's master programmes that was legally introduced by government standards. As a result, we concluded that the changes of education standards mostly meet expectations of master programmes contenders. However, the contenders will succeed in higher school only if their motivation is enough strong and appropriate.
\end{abstract}

\section{Introduction}

The national higher professional education system in Russia have been changed for last three decades. It is directly concerned architectures' professional education. In the early 2000s we faced the attempts of using educational elements indicated at the Bologna declaration. The next step in the middle 2000s was mandatory introduction of two level higher educational system. Architectures' educational programmes' structure and content has been changed simultaneously. Universities' personnel policy and teaching equipment requirements has been revised as well. In accordance to national educational standards the crucial target of the changes is proper alumnus' professional competencies. However, we assume that the correct content and the appropriate structure of educational programmes are not enough for students' high learning results. Teaching approaches, methods and technics should meet the students' motives and expectations concerning their professional value at a labor market but at the same time teaching methods should be in frame of legally introduced requirements of national educational standards as well.

\section{Research Methodology and Statistics}

\footnotetext{
* Corresponding author: kuzmina2003@bk.ru
} 
The analysis of data collected during survey as well as analysis of national educational standards were the basis for interpretation and conclusions. We rely on theoretical researches of widely recognized authors, including the personal motives studies' results.

The value, essence and content of personal needs and motives deeply examined. Experts consider the personal needs (in a context of personal request for something) as a complicated hierarchical system $[1,2,3]$. The system includes (we quote not the full list) needs of personal security, affiliation, esteem and self-esteem, cognition interests, selfactualization. We strongly believe that education nowadays should be seemed as a key and an essential element to meet those needs.

For instance, personal security could be considered as absence of economic insolvency risk and therefore depends on personal professional education level. Affiliation means being involved into groups with appropriate and similar employment experience, professional interests, mindset and attitudes, knowledge and skills. Cognition interests are directly meet by learning, education and self-education process. Self-actualization logically includes the process of knowledge, skills, education development. To sum up, professional education (including higher professional education) is the crucial way to meet present-day basic personal needs.

Persons' needs forms persons' motives. In their turns, motives work as inspiration, impulses and the reasons for activity. Some expert say that motives are the definite forms of personal needs $[4,5,6]$. In view of this fact students' motives to enrol the university are the set of definite reasons that encourage them to choose certain programmes and help them to make their needs come true.

\section{Results}

In that context it seems interesting to summarize results that obtained during our last year survey regarding motives of first year master programmes students from universities of St. Petersburg, including St. Petersburg university of architecture and civil engineering, St. Petersburg university, St. Petersburg university of economics and St. Petersburg state forest technical university [7]. This questionnaire contains several topics. Two of them related to the students' needs and motives.

The students were asked to estimate the value of reasons for them to enroll to master programme using scale from 1 point to 5 , where " 1 " was the lowest level and "5" - the highest. Students' opinions varied as follows: the answer "to extend the campus life" - 2,6 points; "to postpone the employment challenges" - 2,8 point; "to change the obtained professional degree focus" - 2,3; "to shift the focus of obtained professional degree" - 4,6; "to be involved to science research" - 2,8; "master programmes are essential elements of professional education for successful career" - 3,9; "prestige is the reason" $-4,2$ points. We think it's important to comment the difference between 3 and 4 response options. Students who have had the bachelor's degree can apply for master programme in frames of their previous field of study (for instance, student has bachelor's degree at finance and decide to enrol to financial accounting master programme), the option for graduate is to change the field of study (he has had bachelor's degree at economics and he applies for master's programme in jurisprudence).

The second question concerning motives and reasons were devoted to the expectations regarding results that could be obtained by master's programmes candidates. The estimation approach was the same - five-points scale. The findings are: "nothing would change" - 1,6 points; "certificate is only result" - 2,2; "new essential professional knowledge and skills are results" - 4,5 points; "my intelligence level will increase" - 4,6; "new professional social network will be obtained" $-4,8$; "the career potential will be increased" $-3,6$; "it's the stage of personal growth" $-2,8$. 
Thoughts we described above lead to the conclusions regarding the value and weight of follows main groups of master programmes students' education motives: firstly, the formal proceeding of future career development (certificate, diploma) - moderate level; secondly, the substantive content of programmes (new knowledge, skills, networks) was evaluated as more than moderate; thirdly, personal inclinations (personal growth, aptitude for research) shows moderate level.

\section{Discussions}

Usually persons motives are classified as internal and external $[8,9,10]$. The living conditions determine external person's motives, internal motives based on personal needs. However, the motives that we mentioned above in our results could be defined as internal, external and, from our point of view those that we classify as motives of mixed essence. The responses "certificate is result" and "the career potential will be increased" are external motives. It means that so called "formal" motives was born by influence of students living conditions in a society. The responses "to be involved to science research" and "it's the stage of personal growth" we can describe as internal motives. All other motives are motives of mixed essence. This group was highlighted and proposed for students during survey, this group was evaluated by interviewees as important. The reason of this result, we assume, is the fact that most of the motives connected with personal needs but at the same time they were born, fed and fitted by actual social and economic environment of students' everyday life.

For example, motive "new ... professional knowledge and skills are results" from one hand, belongs to person's cognition interests, and his self-actualization tendency, but from the other hand those personal needs are developed and conscious under the influence of requirements from potential employer. Another example concerns the motive "the career potential will be increased". A person tends to develop his self-esteem and cognition interest but in frames of and in accordance with the employer's expectations. The next one - "new professional social network ..." partly respond the affiliation needs, but in addition are positively related to the contemporary significance of professional networks in a career within the context of digital economics' realities.

According to the data pointed out above, internal motives, which was formed under the influence of mature assessment of formal and essence external professional requirements, could be considered as key factors for enrolling to the master programmes. Experts note that the motivation of described nature is the most effective for education process and education results. In terms when socially caused educational targets coincidence with personal caused education motive we obtain the most effective and successful interaction between teaching tools (teaching methods, instruments, approaches) and objects of study (content of discipline and the way of tracking it) [11,12]. In other words, the requirements of present-day national education standards (as educational tools and educational terms according Milman [10]) are carrying out by master programme's student who has motives described above. It's seemed interesting to describe briefly the crucial current trends in the education programmes development, which was recently introduced by laws, and make an analysis of correspondence level between the students' expectations and programmes terms.

In our previous papers (for instance, $[11,13]$ ) we have already made some conclusions concerning trends in educational standards development. Among other facts we highlighted the changes in programmes structure. To illustrate the tendency, we could turn to the educational standards in architecture. We have a chance to make conclusions on the base of comparison. The facts are following. The first standard for masters in architecture was published in 2010. It was supposed that students needed to get 60 credits by disciplines, 45 credits by placement period. Later, in 2015 (standard "three plus 
generation") the credits from disciplines increased up to 66-69 and placement period remained the same. But the amount of auditorium work wasn't introduced. All over the world the changes and trends in teaching methods nowadays are similar: educational process tends to include more project work, team work and independent studying. However, it doesn't mean that theoretical models and methods are not essential for graduate professional competencies, but the approaches to models of taking knowledges has changed: credits to get have increased but contact hours at a curriculum period have decreased.

As we mentioned above, the professional higher education reforming process has ongoing nature. From the one hand, this is very positive trend which enable the education to follow the current changes in professional and science spheres, which essential and vital for education. From the other hand, the changes in educational standards' requirements has become permanent challenges for universities and for teaches.

Thus, present days we face a new challenge that is the set of new educational standards - "the standards of third and double plus's generation". Some of those new master's standards at the end of 2017 and in 2018 was officially introduced by laws and are obligatory for universities. For example, standards in math (4 standards), in computer and information sciences (3 standards), chemistry (2 standards), architecture design construction (4 standards, including standard in architecture), computer science (4 standards), music arts (6 standards), education and pedagogical sciences (4 standards). Although, some educational standards for master level education we have yet as published drafts, including standards in economics, standards in management, in linguistics and philology.

It seems interesting that in drafts and in new standards the approach to requirements concerning the structure of educational programmes changed have been revised. Let us depict this based on architecture's standard. If we take a look at the history of changes the picture will be following. As we said above, standard of 2010 proposed 60 disciplines credits and 45 placement credits, standard of 2015 - respectively 69 and 45 . From last year (standard of 2017) the frames of disciplines became no less than 74 and placement period no less than 30 credits. As a result, we can conclude that last standard reserved a little less than 25 percent more educational work for disciplines in comparison with period 20102014.

Let us compare the trend with standards in other fields. Linguistic: firstly, master standard of 2010 told that students are expected to collect 50-60 credits by disciplines, 4852 credits at placement period. Then from the 2016 masters has to absorb 57-60 credits by disciplines and 51-57 credits at placement period. Finally, according to the draft (2017) - no less then 90 discipline's credits and no less than 10 placement credits. Economics. From the 2010 - discipline's credits were between 50 and 70, placement credits between 45 and 50. From 2016 - discipline credits are between 57 and 63, placement credits are between 4857. Today at draft we have only one side limits - no less then 51 credits by discipline and no less then 16 credits by placement period.

From our point of view, from the 2015-2016 at standards of "third plus generation" the placement period was particularly highlighted. Lawmakers tried to enhance students' professional skills through the connection "education - professional activity" or in other words "education - business". However, the fact that masters are persons who deal with analyses, research, pedagogical sides of professional activities has given rise to the perception that theoretical knowledge still vital for the graduate of such level of higher education. In addition, the requirements regarding contact, distance and self - learning teaching methods are not legally revealed in detail, the requirements regarding universities' facilities for distance learning and electronic learning environment have been tightened. It 
means that in reality we will have more and more self - learning educational methods and approaches for master programmes' students.

But some more conclusions should be made because of master programmes standards changes. The structure of masters' programmes in detail are not introduced by published drafts. Only limits "no more" are set. As a result, universities are those decision - making structures that would be responsible for content, level and depth of theoretical education as well as of kinds, content, targets and evaluating of master students' placement period. So, the difference between master programmes' in different university would be include not only content of graduate knowledge and skills but in addition, unfortunately, the volume of knowledge. Subsequently, it could happen that motivation of enrollees of leading universities and universities of middle-level would become different.

If we turn back to discussion about educational standard changes, the core results of teaching, which are claimed by educational standards, has shifted. The list of professional knowledge is excluded from the "standards of third generation" $(2015,2016)$. For example, the master of architecture (educational standard 2010) was expected to "know the problems of innovative (conceptual) design; the problems of specialized areas of design ("barrierfree", "earthquake-resistant", "climate-zoned", "energy-efficient", "eco-friendly")". Standards of 2015-2016 supposed that graduate could succeeded in integration of different kind of theoretical information to professional every day activity, implement and develop theoretical interventions for the real professional cases.

Let us illustrate this statement with competencies of architecture master (standard 2015): "the ability to develop and to be the leader of the development of design solutions based on research of an innovative (conceptual), interdisciplinary and specialized nature using modern methods and involving the knowledge of various sciences". Thus, new approach presumed that graduate apply their theoretical knowledge in professional practice activity, including scientific, pedagogical, administrative, analytical kinds of work.

The standard of "three plus" decreased the list of competencies and divided them into two the large groups: universal (six items) and general professional (art-graphic, designanalytical and general engineering) (six items) competencies. For example, general engineering: "able to apply the methods of determining the technical parameters for projected objects, using certain software". As you see the requirements became more complex but more specific.

In addition, to reach target points of graduates' competencies valid educational standards introduced new requirements for teaching and governing staff qualities, including real professional experience, participation in research, development and innovation (RDI) projects. These qualities are aimed to encourage university teachers to involve students to the RDI, create atmosphere for team-working and self-learning. Requirements regarding universities' teaching facilities and equipment focus at students' online studies and students' self-studies development. As a result, we came to the conclusions that all mentioned above educational standards requirements provide opportunities for master programmes' students to study with minimum contact hours and enable them to specialize on particular aspects of subject, deepen their knowledges according to their interests and needs.

\section{Conclusions}

The format of master education deeply regulated by national educational standards. We have analysed the most visible trends of educational condition changes that has been introduced recently and made conclusions about mainstream - self- and on-line education that closely turned to the practice needs of economy and science. 
However, current conditions of national masters' education lead to professional competencies building only in frames of Milman model [10], where the motives of master student coincide with targets of education. In other words, the competencies' requirements of masters' educational standards in any spheres of science can be fulfilled only by high motivated students. The survey results showed that expectations regarding the strong education motives of master programmes' candidates are enough satisfying and in prospect the master programmes' graduates would have enough professional competencies.

\section{References}

1. D. Boyd, H. Bee, Lifespan development, 7-th edition. (Pearson, 7 edition, 2014)

2. Wendy L. Dunn, Grace J. Craig, Revel for Understanding Human Development, 4-th edition. (Pearson, 2019).

3. A. H. Maslow, Motivation and Personality. (New York: Harper \& Row, 1954).

4. A. H. Maslow, A Theory of Human Motivation. Psychological Review. 50. 370-396. (1943)

5. P. T. Young, Motivation of behaviour. (New York: John Wiley \& Sons, 1936).

6. J. Nuttin, Motivation, planning, and action. A relational theory of behavior dynamics. (Leuven University Press; Erlbaum, 1984)

7. URL: https://www.survio.com/survey/d/Q5B4H6U2D3J1P3T4M Referred to 28.09.2018

8. Ch. N. Cofer, M. H. Appley, Motivation: Theory and Research. (New York, London, Sydney: John Wiley \& Sons, 1967).

9. E. A. Skinner, M. J. Belmont, Journal of educational psychology, 85, 4, 571-581 (1993)

10. V. E. Milman, Learning activity motives. Phycology problems. 5, 129-139 (1987)

11. N. Morozova, A. Pimenova, The problems of present-day economics, 3, 215-218 (2017).

12. A. Evmenov, S. Kuzmina and V. Vlasova. MATEC Web of Conferences, 170, 01033 (2018)

13. L. Svatovskaya, A. Sychova, M. Sychov, V. Okrepilov. MATEC Web of Conferences. 53, 01024 (2016). 